Article

\title{
The EU ETS and Dynamic Allocation in Phase IV-An Ex-Ante Assessment
}

\author{
Vicki Duscha \\ Fraunhofer Institute for Systems and Innovation Research, Breslauer Strasse 48, 76139 Karlsruhe, Germany; \\ v.duscha@isi.fraunhofer.de; Tel.: +49-721-6809-226
}

Received: 20 December 2017; Accepted: 31 January 2018; Published: 9 February 2018

\begin{abstract}
Fear of lowering firms' competitiveness and carbon leakage is the reason for large amounts of allowances in the European Union's Emissions Trading System (EU ETS) still being allocated for free. At the same time, unadjusted free allocation of allowances in times of economic recession is partly responsible for the large surplus of allowances that has cumulated in the EU ETS and that is lowering prices in the market. For Phase IV, the introduction of dynamic allocation has been proposed to react to significant changes in production, to prevent the accumulation of further surplus on the one hand and to protect installations from severe underallocation on the other. A reserve of about 400 million allowances is planned for that purpose. This paper analyses the demand for certificates from this reserve under different assumptions on production development as well as different design options for Phase IV. The analysis builds on freely available allocation data from Phase III along with projections of production trends from different time periods in the past. In most of the scenarios, the 400 million allowances are sufficient to fulfil demand for allowances from dynamic allocation until at least the second half of Phase IV (often even for the whole of Phase IV). Even though certain aspects analysed are now not fully compatible with the agreed-upon Phase IV revision, the analysis indicates that the amount of allowances foreseen for dynamic allocation is sufficient for Phase IV. In particular the threshold value of $10 \%$ that was introduced in the legislation will ensure that the demand of allowances is likely well below the demand found in the different scenarios in this analysis that neglects this threshold value.
\end{abstract}

Keywords: European Union's Emissions Trading System (EU ETS); dynamic allocation; Phase IV; ex-ante; assessment

\section{Introduction}

For over 10 years, the EU Emissions Trading System (EU ETS) has constituted the key climate policy instrument in the EU. Building upon the principle of cap and trade, it limits the emission of greenhouse gases-mainly $\mathrm{CO}_{2}$ - in major emitting sectors such as power generation, refineries, and energy-intensive industry, covering around $45 \%$ of the EU's total greenhouse gas emissions. Installations covered by the system are obliged to provide allowances for their annual emissions. To achieve emission reductions at the lowest possible costs, firms are allowed to trade emission allowances-so-called EU allowances "EUAs" with each other.

A key issue from the introduction of the instrument until today is the allocation of EUAs to installations. While in the first years of the EU ETS, the majority of allowances were allocated free of charge based on historic emissions ("grandfathering"), the allocation system was changed in Phase III (2013-2020). From the beginning of Phase III onwards, auctioning of allowances presents the key allocation methodology. However, installations from the refineries and industry sector-which are exposed to international competition and therefore deemed to be in danger of carbon leakage-continue to receive allowances free of charge based on benchmarks. Those benchmarks, which were especially 
developed and designed for the EU ETS, present a specific emission value per ton of pre-defined product, independent of the installation's specific emissions per ton of that product. Free benchmark allocation thus allows installations to be exempt from the full costs of facing the carbon price from the EU ETS (which does not affect installations from outside the EU), while at the same time keeping up the incentive to reduce emissions if abatement costs are low compared to the market price for EUAs. Reducing emissions increases an installation's share of free allocation and hence reduces the amount of allowances an installation needs to buy on the market.

While the revision for Phase IV (starting in 2021), which was adopted in November 2017, foresees a continuation of the benchmarking allocation for carbon-leakage-exposed industry, it also introduces a number of changes to the allocation methodology. Those changes apply to the calculation methodology in general, as well as to the specific benchmarking values. The analysis in this paper concentrates on one particular change in methodology proposed by the Commission in July 2015- the introduction of a partly dynamic allocation [1].

So far, in Phase III, allocation was based on fixed benchmark values and historic production levels in a pre-defined base period-the most up-to-date information on production at that time. However, the time lag between calculation of free allocation and the year of allocation can be rather large- - up to 14 years in case of Phase III. As production can change significantly between years-as could, for example, be seen in the years of economic recession-the production data used to calculate free allocation can significantly differ from actual production in the year of allocation. In Phase III, this resulted in large free allocations in some years due to the economic downturn with significantly lower production. This inflexibility in the free allocation of allowances is partly responsible for the large surplus of allowances in the market.

In Phase IV, the system of free allocation is continued, but with slight adaptations. Instead of having one eight-year-period, Phase IV is split up into two five-year periods (2021-2025, 2026-2030) including two five-year base periods (2013-2017, 2018-2022). This way, more up-to-date production data can be used. Further, the proposal foresees an update of the benchmark values to reflect efficiency improvements over time. Instead of collecting new data to calculate new benchmark curves (a timeand resource-consuming process), the proposal suggests a fixed updating factor of $1 \%$ p.a., only for sectors with significantly higher or lower efficiency improvements, the factor can be chosen to be higher $(1.5 \%)$ or lower $(0.5 \%)$. For products on the carbon leakage list, the full benchmark is allocated per ton of product. For products not exposed to carbon leakage, only $30 \%$ of the full benchmark is allocated per ton of product. As in Phase III, it is possible to apply a cross-sectoral correction factor in case the overall allocation based on benchmarks is higher than the pre-determined amount of allowances for free allocation.

The most important adaptation of allocation regulation within the proposal is a change to the new entrants reserve (NER). In contrast to the current version of the NER, it shall apply not only to new entrants, closures, and changes in capacity, but also to significant changes in production. This implies that allocation is no longer fixed for a specific period, but that allocation can adapt dynamically to production developments. This dynamic element shall help to further protect industry in case of significant production increases. At the same time, it allows allowances to be kept out of the market in case of significant production decreases to limit over-allocation. While all production changes could generally result in the adaptation of allowances allocation, it seems more likely that a threshold value will be applied to limit the application of the dynamic allocation to cases of significant changes in production. Around 400 million allowances are kept aside for these purposes.

This paper presents an analysis of the range of the reserve of 400 million allowances foreseen to cover for the additional allowance demand for the dynamic allocation. Allocation data for Phase III is used to estimate the benchmark-based allocation in Phase IV, taking the proposed changes to benchmark values into account. Based on those estimated allocation figures and by making assumptions on the future development of production, allowances demand from and supply to the 
reserve are estimated, and duration of the reserve is calculated. Variation of benchmarking rules for Phase IV and development of production allow the isolation of different effects.

To our knowledge, this is the first analysis looking at dynamic allocation in the EU ETS and the demand for allowances in detail. The idea of the dynamic allocation and its characteristics are discussed in [2]. Reference [3] looks at the effects of dynamic allocation for different sectors, in particular the effect on overall allocation and carbon costs along with the role of the cross-sectoral correction factor. They further analyse the effect of the EU ETS under different designs to forge the decarbonisation of industry, and find that the Commission proposal is not suitable. A purely qualitative analysis of the Commission proposal and of dynamic allocation as one part is provided in [4]. The authors argue that more flexibility with regards to production data is positive, and call for a low threshold value.

The remainder of this paper is organized as follows: Section 2 gives a brief introduction to the EU ETS; Section 3 presents the methodology; Section 4 presents data used and scenarios applied; Section 5 presents and discusses the results; Section 6 summarizes the most important findings; and Section 7 discusses them in light of recent decisions on the review of the EU ETS for Phase IV.

\section{The Phases of the EU ETS and Major Regulatory Changes}

The EU ETS as the key climate policy instrument of the European Union started in 2005. Phase I (2005-2007) was designed as a pilot phase to gain experience with the instrument. At the beginning of the EU ETS, pressure from the system on the regulated entities was limited. In particular, the majority of allowances was allocated to installations free of charge based on historic figures ("grandfathering"). To limit the impact of the decisions made for the pilot phase on later phases, banking of allowances from Phase I to subsequent periods was explicitly not allowed. When it became apparent that the system was heavily over-allocated, the price crashed to close to zero, making allowances for Phase I worthless.

Phase II (2008-2012) overlapped with the first commitment period of the Kyoto Protocol. As in Phase I, free allocation based on grandfathering was the main allocation method under the EU ETS-for industry, but also for most of the power generators. However, as reaction to high windfall profits for electricity providers, free allocation to power generators was reduced and based on benchmarks rather than on grandfathering. Since 2008, it has been possible to bank excess allowances for subsequent trading phases, resulting in a significant build-up of allowances during the years of the financial and economic crisis in Europe and afterwards. The banking provisions in the EU ETS also link all trading phases from Phase II onwards. Therefore, a surplus in allowances piled up in one phase affects future prices too. Due to the financial and economic crises in Europe in the years of Phase II, a significant amount of surplus allowances has accumulated in Phase II, depressing allowances' prices.

Phase III (2013-2020) started in 2013. The most significant change for Phase III was the introduction of allowance auctioning as the main form of allocation. This applies mainly to power generators. For installations deemed to be exposed to the risk of carbon leakage, free allocation is still possible. However, instead of using historic emissions, the allocation is now generally based on benchmarks. In addition, during Phase III, the market stability reserve is going to start in 2018. It is introduced to limit the amount of free allowances in the market, to reduce the oversupply, and stabilize prices. However, the current design of the market stability reserve does not foresee the cancelation of allowances, but foresees a complete reinjection of allowances within the reserve at a future point in time. As such, the market stability reserve helps to limit the current over-supply, but cumulates large amounts of allowances for future years, keeping prices down.

Phase IV (2021-2030) of the EU ETS will start in 2021. While no major design changes will become part of the EU ETS in Phase IV, a number of smaller changes are foreseen. One of those changes is the introduction of a dynamic element for free allocation being analysed in this paper. Other changes relate to the benchmark values being applied and the formula for measuring the degree of carbon leakage danger. Additionally, the review for Phase IV now allows the cancelation of allowances within the market stability reserve from 2024 onwards. 


\section{Methodology and Data}

The ex-ante assessment of the reserve in this paper is based on the allocation data set from Phase III. In this section, the adaptation of the data set for Phase IV is being presented before Section 4 presents the scenarios that are being analysed.

At the time of analysis, revisions of the EU ETS for Phase IV were still only proposals. This paper presents an analysis of the proposal made by the European Commission in July 2015. In order to be able to perform a quantitative ex-ante assessment of the reserve, a number of assumptions had to be made. They present their own interpretations of the proposal text.

In general, the amount of allowances within the reserve can change for four reasons:

- Demand for allowances from the reserve for new entrants

- Supply of allowances for the reserve from installation closure

- Demand for allowances from the reserve to cover significant production increases (including increases in production capacity)

- Supply of allowances for the reserve due to significant production reductions (including reduction in production capacity due to partial cessation).

In all cases, changes in production are the key factor. Therefore, no differentiation of those four cases was made in the following analysis. Instead, change in production levels was used as the key variable to calculate effects on the reserve.

The methodology to calculate inflows into and outflows from the reserve consists of three steps:

- Step 1: Calculation of basic allocation in Phase III

- Step 2: Calculation of basic allocation in Phase IV accounting for revisions of benchmark values and production developments

- Step 3: Calculation of allocation from the reserve in Phase IV.

The calculation was based on installation-specific information on allocation in Phase III and information on the sector classification of individual installations (NACE sectors (Statistical classification of economic activities in the European Union)). Information on allocation was taken from the European Transaction Log (EUTL), and information on NACE sector classification was taken from the Commission homepage (http:/ / ec.europa.eu/clima/policies/ets/cap/leakage/docs/installation nace_rev2_matching_en.xls). In addition, production indices from Eurostat were used to calculate historic trends and apply them as an estimate of future production developments. The following paragraphs present the methodology in detail.

Step 1: Calculation of basic allocation in Phase III

Basic allocation refers to an installation's allocation purely based on benchmark times production, and not accounting for possible adaptations such as the cross-sectoral correction factor. The calculation of basic allocation in Phase III uses the allocation data set for the years 2013-2020 for all installations available in the EUTL (11.920 at the time of download). The data set (downloaded on 25 August 2015) provides allocation information on a yearly basis. For the years 2013 and 2014, data were adapted from the initial allocation to reflect capacity changes. Therefore, information for those years cannot be used for identification of the basic allocation for Phase III. For the remaining years from 2015 to 2020, allocation $A l l_{i}$ by installation was calculated (by the Commission) as follows:

$$
\begin{aligned}
\operatorname{All}_{i}(t) & =\sum_{j \text { prod in } i, j=C L} \operatorname{Prod}_{i, j}(\text { base period }) * B M_{j} * \operatorname{CSCF}(t) \\
& +\sum_{j \text { prod in } i, j \neq C L} \operatorname{Prod}_{i, j}(\text { base period }) * B M_{j} * C L(t) * \operatorname{CSCF}(t)
\end{aligned}
$$

for installation $i$, product $j$, for year $t$. Prod $i, j$ relates to production of product $j$ in installation $i, B M_{j}$ is the benchmark value for product $j, C L(t)$ is the linear reduction factor of free allocation for installations not at risk of carbon leakage, and CSCF is the yearly cross-sectoral correction factor. 
While benchmark values are known, information on the production of specific products within individual installations is not freely available. Therefore, basic allocation could not be calculated directly, but needed to be calculated indirectly by using the freely available information. As the cross-sectoral correction factor and the linear reduction factor on free allocation for firms not exposed to the risk of carbon leakage are known, the product of production and benchmark value can be determined differentiated by risk of carbon leakage or not at risk of carbon leakage for each firm. First, the cross-sectoral correction factor-which is applied regardless of whether a product is exposed to carbon leakage-is eliminated from the equation, which gives $A l l_{n o C S C F, i}$. By calculating the differences of $A l l_{n o C S C F, i}$ between years, basic allocation for products can be calculated as

$$
\sum_{j \text { prod in } i, j \neq C L} \operatorname{Prod}_{i, j}(\text { base period }) * B M_{j}=\frac{\left(A l_{n o C S C F, i}(t)-A l l_{n o C S C F, i}(t-1)\right)}{(C L(t)-C L(t-1))}
$$

for products not exposed to the risk of carbon leakage, and

$$
\begin{aligned}
\sum_{\text {prod in } i, j=C L} & \operatorname{Prod}_{i, j}(\text { base period }) * B M_{j} \\
& =\operatorname{All}_{n o C S C F, i}(t) \\
& -\sum_{j \text { prod in } i, j \neq C L} \operatorname{Prod}_{i, j}(\text { base period }) * B M_{j} * C L(t)
\end{aligned}
$$

for products exposed to the risk of carbon leakage.

Because the calculations are based on differences, the values for six years (2015-2020) provide five estimates for basic allocation in Phase III per installation. In case of slight variations between values, the mean was calculated and applied for further calculations. Small negative values were corrected to zero.

Step 2: Calculation of basic allocation in Phase IV

The basic allocation of Phase III as calculated in Step 1 was the basis for further calculations. In Step 2, the basic allocation of Phase IV was derived by applying changes for benchmark values and production levels in the new base periods. Base periods for Phase IV are defined as 2013-2017 for the first part of Phase IV and 2018-2022 for the second part of Phase IV. They provide production values for Phase IV allocations based on production trends provided by Eurostat and forward projection of historic trends. By default, benchmark values were adapted by $15 \%$ for the first part of Phase IV and $20 \%$ for the second part.

Step 3: Calculation of allocation from the reserve in Phase IV

Calculation of allocation from the reserve in Phase IV also requires an estimate of production changes between the base period and the allocation period in Phase IV. This is based on the same historic production trends and forward projections thereof as applied in Step 2. Having determined the change in production $x_{i}$, allocation from the reserve RAll can be calculated as

$$
R A l l_{i}(t)=A l l_{i}(t) * x_{i}
$$

This methodology allows the calculation of basic allocation for all installations, except for those receiving free allowances for heat exported to private households (Art. 10,3 Commission Decision 2011/278/EU on free allocation of allowances). For those installations, only data for 2019 and 2020 were used to determine basic allocation. For these two years, the allocation under this article was lowest to limit the impact of these additional free allocations.

To validate the data set, in addition to calculations of future allocation, the data set was also used to calculate historic initial final allocation for Phase III. The validation showed that the calculated data 
set matches data provided by the European Commission on basic allocation with a deviation of less than $0.1 \%$. Hence, it can be assumed that the derived basic allocation matches pretty well with the actual basic allocation used by the Commission. Slight differences can be explained by the mentioned additional free allocation for heat generation provided to private households, which linearly decreases over Phase III and reaches almost zero in 2020 for Germany. If no similar regulation is applied for Phase IV, basic allocation in Phase IV should not be affected by these free allocations for heat delivered to private households. An overview is provided in the Appendix A to this paper.

\section{Scenarios}

Several different scenarios were constructed to account for different developments and decisions in the context of regulation for Phase IV. Variables taken into consideration for the different scenarios were:

- Benchmark values: by default, a 1\% p.a. correction was assumed for benchmark values, resulting in an adaptation of benchmark values from Phase III of $15 \%$ and $20 \%$, respectively, for the two parts of Phase IV. In addition, a sensitivity analysis applied a smaller correction of $0.5 \%$ p.a., resulting in an adaptation of benchmark values from Phase III of $7.5 \%$ and $10 \%$. No sensitivity was calculated for the possible upper-end of the adaptation of benchmark values, as it was seen as unlikely at the time of analysis.

- Production level in base period: Different assumptions were applied regarding the production level in the two base periods for Phase IV. All were based on trends derived from the Eurostat production index as presented in the last section. However, different time periods from 2005-2016 to 2012-2016 were used to calculate the trend.

- Cross-sectoral correction factor: No matching of calculated allocation to the overall cap and the share being available for free allocation was done. Instead, different scenarios for the cross-sectoral correction factor were calculated and compared. The two possibilities looked at were a linearly decreasing cross-sectoral correction factor from 1 to 0.8 between 2021 and 2030, and no application of a cross-sectoral correction factor at all.

- Use of reserve/production levels in the two trading periods of Phase IV: The main factor determining the use of the reserve for dynamic allocation was the difference in production between base period and trading period. Due to data availability issues, the proposal analysed here foresaw a time shift of eight years on average between the base period and the trading period (or three years between the last year of the base period and the first year of the trading period. Again, different assumptions were made to analyse the effects on the results for the reserve. On the one hand, the differences in production were calculated based on the production trend applied within the analysis. In addition, two fixed differences (5\% and $10 \%)$ were also analysed. They were mostly higher than the values calculated from historic trends.

Differences in production levels between base and trading period were interpreted as net-differences. In some cases, some installations/sectors may face negative growth and hence lose allowances to the reserve, while others face positive growth and hence receive allowances from the reserve. For our analysis, only the net effect on the reserve mattered.

There are additional factors that can have an impact on the reserve, but which are not varied in the following analyses:

- Exposure of a sector to carbon leakage: For the following analyses, it was assumed that the same carbon leakage classification as in Phase III applied.

- Threshold: While it seems reasonable to assume that only significant production changes above a certain threshold allow for the use of the reserve, in the following analyses, it was assumed that all changes in production were relevant for the reserve.

- Extent of additional allocation: It was further assumed that the total difference in production was compensated by the reserve. 
Combining the different variations resulted in the analysis of seven scenarios:

- Reference scenario: adaptation of benchmark values by $1 \%$ p.a. but constant production levels from Phase III (i.e., production growth rate assumed to be $0 \%$ p.a. until the end of Phase IV)

- Base case: adaptation of benchmark values by 1\% p.a., production trend from 2010-2016 used for calculation of production levels in base periods of Phase IV

- Scenario P1: adaptation of benchmark values by 1\% p.a., production trend from 2005-2016 used for calculation of production levels in base periods of Phase IV

- Scenario P2: adaptation of benchmark values by 1\% p.a., production trend from 2008-2016 used for calculation of production levels in base periods of Phase IV

- Scenario P3: adaptation of benchmark values by 1\% p.a., production trend from 2012-2016 used for calculation of production levels in base periods of Phase IV

- Scenario BM0.5: adaptation of benchmark values by $0.5 \%$ p.a., production trend from 2010-2016 used for calculation of production levels in base periods of Phase IV

For each of those scenarios, two alternatives were analysed: one with a linearly decreasing cross-sectoral correction factor from 1 to 0.8 between 2021 and 2030 (alternative "a"), and one without the application of a cross-sectoral correction factor (alternative " $b$ "). Additionally, three different cases regarding the difference in production levels between the base periods and the trading periods of Phase IV were analysed: calculated based on the applied production trend, an increase of $5 \%$, and an increase of $10 \%$. Table 1 summarizes the analysed scenarios.

Table 1. Scenario overview.

\begin{tabular}{|c|c|c|c|c|c|c|}
\hline Scenario & Benchmark & Production Trend & Carbon Leakage & $\begin{array}{l}\text { Cross-Sectoral } \\
\text { Correction Factor }\end{array}$ & $\begin{array}{l}\text { Production Difference } \\
\text { Base-Trade Period }\end{array}$ & $\begin{array}{l}\text { Threshold } \\
\text { and Extent }\end{array}$ \\
\hline Reference & $15 / 20 \%$ & Constant to Phase III & Phase III & Linearly decreasing $1-0.8$ & $0 \% 5 / 10 \%$ & None/total \\
\hline Base case a & $15 / 20 \%$ & 2010-2016 & Phase III & Linearly decreasing $1-0.8$ & Production trend $/ 5 / 10 \%$ & None/total \\
\hline Base case $b$ & $15 / 20 \%$ & 2010-2016 & Phase III & none & Production trend $/ 5 / 10 \%$ & None/total \\
\hline P1 a & $15 / 20 \%$ & $2005-2016$ & Phase III & Linearly decreasing $1-0.8$ & Production trend $/ 5 / 10 \%$ & None/total \\
\hline P1 b & $15 / 20 \%$ & 2005-2016 & Phase III & none & Production trend $/ 5 / 10 \%$ & None/total \\
\hline $\mathrm{P} 2 \mathrm{a}$ & $15 / 20 \%$ & 2008-2016 & Phase III & Linearly decreasing $1-0.8$ & Production trend $/ 5 / 10 \%$ & None/total \\
\hline $\mathrm{P} 2 \mathrm{~b}$ & $15 / 20 \%$ & 2008-2016 & Phase III & none & Production trend $/ 5 / 10 \%$ & None/total \\
\hline P3 a & $15 / 20 \%$ & 2012-2016 & Phase III & Linearly decreasing $1-0.8$ & Production trend $/ 5 / 10 \%$ & None/total \\
\hline $\mathrm{P} 3 \mathrm{~b}$ & $15 / 20 \%$ & $2012-2016$ & Phase III & none & Production trend $/ 5 / 10 \%$ & None/total \\
\hline BM0.5 a & $7.5 / 15 \%$ & 2010-2016 & Phase III & Linearly decreasing $1-0.8$ & Production trend $/ 5 / 10 \%$ & None/total \\
\hline BM0.5 b & $7.5 / 15 \%$ & 2010-2016 & Phase III & none & Production trend $/ 5 / 10 \%$ & None/total \\
\hline
\end{tabular}

Table 2 shows the production trends (aggregated on the EU level) in the different scenarios as calculated based on differing historic periods. The trends were calculated on a country and sector level and applied to the installations based on country and NACE code matching.

Table 2. Production trends in the EU.

\begin{tabular}{cccccccc}
\hline $\begin{array}{c}\text { Historic } \\
\text { Period }\end{array}$ & $\begin{array}{c}\text { Annual Growth } \\
\text { Rate (Starting 2017) }\end{array}$ & $\begin{array}{c}\text { 1. Base Period } \\
\text { P IV-Change } \\
\text { to Base Period } \\
\text { P III }\end{array}$ & $\begin{array}{c}\text { 2. Base Period } \\
\text { P IV-Change } \\
\text { to Base Period } \\
\text { P III }\end{array}$ & $\begin{array}{c}\text { 1. Trade Period } \\
\text { P IV-Change } \\
\text { to Base Period } \\
\text { P III }\end{array}$ & $\begin{array}{c}\text { 2. Trade Period } \\
\text { P IV-Change } \\
\text { to Base Period } \\
\text { P III }\end{array}$ & $\begin{array}{c}\text { 1. Trade Period P } \\
\text { IV-Difference } \\
\text { between Trade } \\
\text { and Base Period }\end{array}$ & $\begin{array}{c}\text { 2. Trade Period P } \\
\text { IV-Difference } \\
\text { between Trade } \\
\text { and Base Period }\end{array}$ \\
\hline $2005-2016$ & $0.57 \%$ & $-9.85 \%$ & $-8.59 \%$ & $-7.65 \%$ & $-4.32 \%$ & $2.44 \%$ & $4.67 \%$ \\
$2008-2016$ & $-0.23 \%$ & $-9.97 \%$ & $-11.16 \%$ & $-12.16 \%$ & $-12.84 \%$ & $-2.42 \%$ & $-1.89 \%$ \\
$2010-2016$ & $0.87 \%$ & $-9.79 \%$ & $-7.47 \%$ & $-5.67 \%$ & $-0.8 \%$ & $4.57 \%$ \\
$2012-2016$ & $1.31 \%$ & $-9.77 \%$ & $-6.06 \%$ & $-3.04 \%$ & $4.26 \%$ & $7.45 \%$ \\
\hline
\end{tabular}

Source: own calculations.

\section{Results}

This section presents the results from the different scenarios. It starts with the presentation of the calculated allocation for Phase IV before presenting the demand/supply from the reserve and the conclusions regarding the range of the reserve proposed by the Commission.

Table 3 shows the calculated allocation for Phase IV, differentiated by first and second trading period of Phase IV. In contrast to the calculated indicative final allocation for Phase III, the calculated 
free allocation for Phase IV was low in almost all scenarios. In particular for the first part of Phase IV (2021-2025), the allocation in most scenarios was between 590 and 620 million allowances, and hence significantly lower than the 670 million allowances in the year 2020. Even in case of the BM scenario, the allocation for the first part of Phase IV reached the allocation in the year 2020 only for the scenario without the application of a cross-sectoral correction factor. Additionally, for the second part of Phase IV, allocation remained below the allocation in Phase III. Two effects led to this result: first, as Table 2 shows, production in all but one base period for the Phase IV scenario was below the production level in the Phase III base period. In addition, the adaptation of the benchmark values also led to a decrease in free allocation. In total, these two effects resulted in a lower free allocation of 50 to 80 million allowances and lower free allocation even in the scenarios without application of a cross-sectoral correction factor.

The limited variation for production in the first part of Phase IV is also reflected in the calculated values. Due to the availability of historic values up to the year 2016, only one year (2017) needed to be estimated to calculated production levels for the first base period for Phase IV. As a result, the calculated allocation for the first part of Phase IV was relatively stable between the different scenarios with regards to assumptions on future production levels. Differences in calculated free allocation arose for different assumptions on the benchmark update ("BM0.5" scenarios) and in the reference scenario, which applied production levels from Phase III.

Table 3. Calculated annual free allocation in Phase IV under the EU Emissions Trading System (ETS).

\begin{tabular}{cccc}
\hline Scenario & $\begin{array}{c}\text { Calculated Indicative Final } \\
\text { Allocation 2020 (m Allowances) }\end{array}$ & $\begin{array}{c}\text { Calculated Free Allocation Phase } \\
\text { IV, 2021-2025 (m Allowances) }\end{array}$ & $\begin{array}{c}\text { Calculated Free Allocation Phase } \\
\text { IV, 2026-2030 (m Allowances) }\end{array}$ \\
\hline Reference & 672 & 661 & 550 \\
Base case a/b & 672 & $592 / 620$ & $507 / 601$ \\
P1 a/b & 672 & $592 / 619$ & $500 / 592$ \\
P2 a/b & 672 & $591 / 618$ & $485 / 574$ \\
P3 a/b & 672 & $592 / 620$ & $516 / 611$ \\
BM0.5 a/b & 672 & $644 / 674$ & $570 / 675$ \\
\hline
\end{tabular}

Source: own calculations.

Results on the demand from and the supply into the reserve are presented in Table 4.

The highest demand for certificates could be found in the case of a $10 \%$ increase in production between base and trading period. Demand varied between 60 and 70 million allowances p.a. for the first part of Phase IV and 50 and 70 million allowances p.a. for the second part of Phase IV. Higher demand was only found in Scenario P3, which resulted in a demand of 63 and 74 million allowances p.a. for the period 2026-2030. This was a result of the difference in production levels between the base and trading period in the scenarios, which was calculated to be around $11 \%$. Supply into the reserve and hence a filling up of the reserve was found in Scenario P2. Again, the difference in production levels was the relevant factor, which was found to be slightly negative in this case, in contrast to the other scenarios. P2 was also the only scenario with a negative p.a. growth rate.

Table 4. Calculated annual allowances' demand/supply from production changes.

\begin{tabular}{|c|c|c|c|c|c|c|}
\hline \multirow{2}{*}{$\begin{array}{c}\text { Scenario- } \\
-\end{array}$} & \multicolumn{6}{|c|}{ Annual Allowances' Demand/Supply from Production Changes (m Allowances) } \\
\hline & Production Trend & $+5 \%$ & $+10 \%$ & Production Trend & $+5 \%$ & $+10 \%$ \\
\hline- & \multicolumn{3}{|c|}{ 2021-2025 } & \multicolumn{3}{|c|}{ 2026-2030 } \\
\hline Reference & - & 33.1 & 66.1 & - & 27.5 & 55.0 \\
\hline Base case $a / b$ & $31.3 / 32.8$ & $29.6 / 31.0$ & $59.2 / 61.9$ & $40.6 / 48.0$ & $25.4 / 30.0$ & $50.7 / 60.1$ \\
\hline $\mathrm{P} 1 \mathrm{a} / \mathrm{b}$ & $16.2 / 16.9$ & $29.6 / 30.9$ & $59.1 / 61.9$ & $25.1 / 29.7$ & $25.0 / 29.6$ & $50.0 / 59.2$ \\
\hline $\mathrm{P} 2 \mathrm{a} / \mathrm{b}$ & $-15.1 /-15.8$ & $29.5 / 30.9$ & $59.1 / 61.8$ & $-10.3 /-12.2$ & $24.2 / 28.7$ & $48.5 / 57.4$ \\
\hline P3 a/b & $50.6 / 53.0$ & $29.6 / 31.0$ & $59.2 / 62.0$ & $62.8 / 74.4$ & $25.8 / 30.6$ & $51.6 / 61.1$ \\
\hline BM0.5 a/b & $34.1 / 35.7$ & $32.2 / 33.7$ & $64.4 / 67.4$ & $54.6 / 54.0$ & $28.5 / 33.8$ & $57.0 / 67.5$ \\
\hline
\end{tabular}

According to these calculations, the 400 million allowances from the reserve were sufficient for Phase IV in most cases, as Figure 1 shows. In all but one scenario, by sticking to historic production trends the reserve was found to contain a sufficient amount of allowances to fulfil the demand 
throughout Phase IV. Moreover, in Scenario P2, the amount of allowances within the reserve increased by 130-140 million allowances between 2021 and 2030. The amount of allowances was not sufficient in Scenario P3, where the allowances from the reserve were used up in 2027 and 2028, respectively. This scenario had the highest annual production growth rate determined, which resulted in a relatively high difference of $7.5 \%$ and $11 \%$, respectively, between production levels in the base period and production levels in the trading period.

In contrast, in all scenarios, a difference in production level of $10 \%$ between the base period and the trading period of Phase IV resulted in the reserve being exhausted in the second part of Phase IV. However, as the analysis of historic production figures showed, such a difference in production levels was unusual in the past-in particular over longer time periods such as 10 years. Only Scenario P3 with a relatively short period of 6 years and with catch-up effects after the economic downturn during the financial crisis showed differences on the same order of magnitude.

The analysis further revealed that the application of a cross-sectoral correction factor had a visible effect on the amount of free allocation. However, this effect was scaled-down when looking at the reserve due to the effects from production differences. As a result, it had no significant impact on the range of the reserve in these calculations.

In light of the analyses, it is important to keep in mind that the figures only present aggregated data for the EU as a whole. Effects in individual countries and sectors can be significant, but they are levelled out when looking at aggregated EU figures.

\begin{tabular}{|c|c|c|c|c|c|c|c|c|c|c|c|}
\hline & 2021 & 2022 & 2023 & 2024 & 2025 & 2026 & 2027 & 2028 & 2029 & 2030 & $>2030$ \\
\hline \multirow{2}{*}{ Reference } & & & & & & & & & & & \\
\hline
\end{tabular}

Figure 1. Availability of allowances from the reserve. light grey: allowances available from the reserve in both scenarios; dark grey: allowances available from the reserve in one of two scenarios; white: not sufficient allowances available from the reserve in both scenarios; three rows per scenario relate to: production trends, $+5 \%,+10 \%$ production.

\section{Insights}

Summarizing the results from the above analysis provides the following insights:

- The average production trend in manufacturing industries in the EU ETS was between $-0.2 \%$ and $1.3 \%$ p.a. in recent years, depending on the period under review. However, values for individual countries and sectors differed significantly. In particular, growth rates for energy- and emission intensive industry sectors iron and steel, cement, and chemicals were low and on EU average even negative.

- Calculated production levels in the two base periods for Phase IV based on historic production trends were below production levels in the base period for Phase III. In the first base period of Phase IV, it was $10 \%$ lower; in the second base period, based on our assumptions the difference was between 6 and $11 \%$.

- Differences in production levels between base period and trading period in Phase IV based on historic production trends were generally between $-2.5 \%$ and $7.5 \%$. Only in one of the scenarios 
was a difference of $11 \%$ reached. This difference significantly influenced the demand from/supply for the reserve.

- The analysis showed a net demand of 16-75 million allowances per annum. One of the scenarios showed a negative production trend, resulting in an increase of the reserve by 130-140 million allowances over Phase IV.

- According to the analysis, the 400 million allowances proposed for the reserve are sufficient to fulfil the demand for certificates up to the year 2027, in many cases until after 2030.

- While the assumptions on growth-in particular the production change between base and trading period-heavily determined the use of the reserve, other factors analysed here had a much less significant effect. In particular, the application of the cross-sector correction factor impacted the scope of the reserve by no more than one year, and similarly the choice of adaptation of benchmark values only showed a significant effect in the case of high production changes of $10 \%$.

\section{Discussion and Outlook}

The analysis presented in this paper addressed the introduction of a dynamic element to free allocation of allowances as proposed by the EU Commission in July 2015 for Phase IV of the EU ETS. The analysis showed that under the assumption of the continuation of historic growth rates, a reserve of 400 million allowances is likely sufficient to meet the supply of allowances due to significant production changes in Phase IV.

In November 2017, the new legislation on Phase IV of the EU ETS passed the trilogue negotiations. Hence, certain regulations are now clearer compared to the time of performing the analyses presented in this paper. Regarding the dynamic reserve, three particular decisions are of relevance. First, the new legislation defines the size of the reserve available for production changes as 200 million allowances from the market stability reserve (MSR) plus an additional amount of allowances not allocated during Phase III. IEAT estimates the amount of allowances in the reserve adding up to around 350 million and thus being slightly lower compared to the amount assumed in the above analysis [5]. However, our calculations show that this changes the year in which allowances will be used up in our scenarios by one or two years at most. Hence, the reserve would still suffice to meet the demand for allowances for at least the first half of Phase IV, and in many scenarios significantly longer.

Second, the directive foresees a threshold value of $15 \%$ calculated as rolling two-year average compared to the base period level. Only production changes on that order of magnitude result in an allocation from or adding of allowances to the reserve. In contrast, the analysis presented assumes that all changes in production result in allocation adjustments. It is likely that many installations will stay below that threshold, in particular in countries with mature economies such as Germany, France, the UK, or the Netherlands. Together, those countries accounted for $40 \%$ of allowances allocated for free in 2016. Hence, it can be assumed that this threshold balances out the slightly smaller amount of allowances compared to this analysis.

Third, the agreed-upon update of the benchmark value is different from the one proposed by the Commission in July 2015, in that values for the flat-rate update lay between $0.2 \%$ and $1.6 \%$ p.a. Smaller adjustments of the benchmark values result in higher overall free allocations, and hence higher demand from the reserve. However, in the BM0.5 scenario, in most cases the reserve was sufficiently equipped to last until after 2030, indicating that the effect of the benchmark update on the reserve was less significant for the use of the reserve compared to other factors such as actual growth rates.

Moreover, the analysis clearly showed that the most important factor for the use of the reserve is the development of growth-the primary reason for the introduction of the dynamic element in allocation.

On a more general note: in theory, emissions trading systems allow to find the most cost-effective abatement potential (The same applies for a carbon tax; however, to introduce a carbon tax (as any other tax) requires a unanimity vote in the European Council, which could not be reached in the past. As the unanimity rule does not apply for the introduction of an emissions trading system in the EU 
and as it should be able to deliver similar results with regards to cost efficiency, the EU decided to introduce an emissions trading system). The creation of a free market for all installations to trade emission allowances with each other while at the same time limiting uncertainties on future caps and design elements for market participants is a key aspect in that. While the dynamic allocation system does not generally affect the market prices—as it has no impact on the overall cap-or significantly increase the uncertainty for market participants, it is nonetheless an additional regulatory adjustment. As such, it increases the complexity of the system and hence the transaction costs, contradicting the idea of having a simple instrument and limited regulation. Future research should address the question of how to limit the regulatory adjustments needed within the EU ETS. Dynamic allocation is a reaction to the uncertainty of future production - uncertainty that cannot be overcome in a market economy). However, the market intervention is only needed because allowances are provided to installations covered by the EU ETS free of charge. Therefore, in light of the development of climate policy around the world, future research needs to address the question under which circumstances the risk of carbon leakage-which provides the justification for the free allocation of allowances to installations-is diminished and free allocation of allowances is no longer needed.

Acknowledgments: This work was partly supported by the German Environment Agency under Grant FKZ 371441504 ("Evaluierung und Weiterentwicklung des EU-Emissionshandels aus ökonomischer Perspektive für die Zeit nach 2020").

Conflicts of Interest: The author declares no conflict of interest. The founding sponsors had no role in the design of the study; in the collection, analyses, or interpretation of data; in the writing of the manuscript, and in the decision to publish the results.

\section{Appendix A}

Validation of data set.

Table A1. Validation of the data set.

\begin{tabular}{|c|c|c|c|c|c|c|}
\hline & 2016 & 2017 & 2018 & 2019 & 2020 & 2016-2020 \\
\hline Indicative final allocation (EUTL) & 760.8 & 737.7 & 715.3 & 693.5 & 672.1 & 3579.5 \\
\hline Estimated ind. final allocation & 760.0 & 737.8 & 715.7 & 693.8 & 672.2 & 3579.4 \\
\hline Differences & 0.9 & -0.1 & -0.4 & -0.3 & -0.0 & 0.1 \\
\hline Absolute differences & 1.5 & 0.5 & 0.4 & 0.3 & 0.0 & 2.7 \\
\hline Absolute differences in $\%$ of ind. final allocation & $0.19 \%$ & $0.07 \%$ & $0.06 \%$ & $0.04 \%$ & $0.00 \%$ & $0.08 \%$ \\
\hline
\end{tabular}

\section{References}

1. European Commission. Proposal for a DIRECTIVE Amending Directive 2003/87/EC Fo Enhance Cost-Effective Emission Reductions and Low-Carbon Investments. Available online: http:/ / eur-lex.europa. eu/legal-content/EN/TXT/?uri=CELEX\%3A52015PC0337 (accessed on 19 December 2017).

2. Borkent, B.; Gilbert, A.; Klaassen, E.; Neelis, M.; Blok, K. Dynamic Allocation for the EU Emissions Trading System. Enabling Sustainable Growth; Finale Report Project Number MARNL14720; Ecofys: Utrecht, The Netherlands, 2014.

3. Jalard, M.; Alberola, E. Free Allocation in the European Emissions Trading System (EU ETS): Identifying Efficient Mechansims Through to 2030; Etude Climat \#51; Institute for Climate Economics: Paris, France, 2015.

4. Macru, A.; Elerbout, M. The EU ETS Structural Reform for Phase 4: Views on the European Commission Proposal; CEPS Carbon Market Forum: Brussels, Belgium, 2015.

5. International Emissions Trading Association (IETA). EU ETS in the Paris Vision. IETA Side Event at COP23/CMP13/CMA2. 16 November 2017. Available online: http:/ /www.ieta.org/resources/COP\%2023/ Side-Event-Presentations/EU\%20ETS\%20side\%20event\%20COP23.pdf (accessed on 8 February 2018).

(c) 2018 by the author. Licensee MDPI, Basel, Switzerland. This article is an open access article distributed under the terms and conditions of the Creative Commons Attribution (CC BY) license (http://creativecommons.org/licenses/by/4.0/). 